\title{
T-cadherin is associated with prognosis in triple-negative breast cancer
}

\author{
DE-DI KONG ${ }^{1}$, MEI-HONG WANG ${ }^{1}$, JIE YANG $^{2}$, LIANG LI $^{3}$, WEI WANG ${ }^{1}$, \\ SHI-BING WANG ${ }^{1}$ and YAN-ZHEN ZHOU ${ }^{1}$ \\ Departments of ${ }^{1}$ Thyroid and Breast Surgery, ${ }^{2}$ Pharmacy and ${ }^{3}$ Pathology, Jining No. 1 People's Hospital, \\ Jining, Shandong 272011, P.R. China
}

Received January 17, 2016; Accepted May 26, 2017

DOI: 10.3892/ol.2017.6505

\begin{abstract}
The purpose of the present study was to assess the prognostic impact of T-cadherin expression in patients with triple-negative breast cancer (TNBC). On the basis of the results of immunohistochemical analysis, 106 patients with operable TNBC were divided into two groups, the T-cadherin-positive group and T-cadherin-negative group. Fisher's exact and $\chi^{2}$ tests were employed to analyze clinical data, which included the association between T-cadherin expression and clinicopathological features and prognosis. The log-rank test was used to examine the impact of T-cadherin expression on the 5-year disease-free survival (DFS) and the 5-year overall survival (OS) of these patients. Kaplan-Meier and Cox regression analyses were introduced to analyze DFS and OS. Compared with the T-cadherin-positive group (58.3, 52.8 and 47.2, respectively; $\mathrm{P}=0.018, \mathrm{P}=0.017$, and $\mathrm{P}=0.047$ ), tumor size $>2 \mathrm{~cm}$, grade II and III (Elston-Ellis modification of Bloom-Richardson grading system), and positive lymph node status were significantly more common in the T-cadherin-negative group compared with the T-cadherin-positive group ( 80.0 vs. $58.3 \%, 75.7$ vs. $52.8 \%$ and 67.1 vs. $47.2 \%$, respectively) $(\mathrm{P}=0.018, \mathrm{P}=0.017$, and $\mathrm{P}=0.047)$. Compared with the T-cadherin-positive group, 5-year DFS and OS levels were significantly lower in the $\mathrm{T}$-cadherin-negative group $(\mathrm{Z}=6.233$, $\mathrm{P}=0.013 ; \mathrm{Z}=5.366, \mathrm{P}=0.021$ ). Multivariate analysis revealed that negative $\mathrm{T}$-cadherin expression was an independent prognostic factor for DFS $(\mathrm{P}=0.009)$ and $\mathrm{OS}(\mathrm{P}=0.048)$. The results of the present study indicated that negative T-cadherin expression indicated a worse prognosis for patients with TNBC.
\end{abstract}

Correspondence to: Dr De-Di Kong, Department of Thyroid and Breast Surgery, Jining No. 1 People's Hospital, 6 Jiankang Road, Jining, Shandong 272011, P.R. China

E-mail: kangtailu@yahoo.com

Key words: T-cadherin, triple-negative breast cancer, clinicopathological features, prognosis

\section{Introduction}

In recent years, the development of comprehensive therapy (surgical resection combined with chemo-, immuno- or radiotherapy) (1) has reduced the mortality rate of patients with breast cancer $(2,3)$. However, the mortality of patients with triple-negative breast cancer (TNBC) remains high (4-6). TNBC is a specific subtype of breast cancer that is distinguished by a lack of estrogen receptor (ER), progesterone receptor (PR), and human epidermal growth factor receptor 2 (HER-2) expression $(7,8)$. TNBC is characterized by aggressive clinical behavior, including early distant metastasis, recurrence, a lack of specific therapeutic targets and poorer prognosis than other subtypes of breast cancer (9-11). Chemotherapy is the primary systemic therapeutic approach for TNBC treatment, although only $\sim 20 \%$ of patients with TNBC are sensitive to chemotherapy (12). To improve the prognosis of TNBC, the molecular and biological mechanisms that underlie its aggressive behavior require clarification. The emergence of novel markers for an effective targeted therapy could change the current TNBC treatment strategies.

The cadherins are a family of cell-surface glycoproteins responsible for mediating calcium-dependent homophilic intercellular adhesion. The adhesive properties of classical cadherin adhesion molecules serve an essential role in the maintenance of tissue (13-16). T-cadherin is an atypical cadherin lacking in the transmembrane and cytoplasmic domains and is linked to the plasma membrane by the glycosylphosphatidylinositol (GPI) anchor (17-19).

T-cadherin expression has been considered to be a useful tool to stratify tumors and identify the degree of T-cadherin involvement in specific steps of cancer progression $(20,21)$. Downregulation of T-cadherin is frequently observed in multiple types of cancer, including ovarian carcinoma (22), gastric cancer (23), colorectal cancer (24), hepatocellular carcinoma (25), bladder transitional cell carcinoma (26), breast cancer (27) and gallbladder cancer (19), and is generally associated with poor patient outcome.

Previous studies have revealed that the process of tumor cell development and invasion, induced by the epidermal growth factor, may be inhibited by the high expression of T-cadherin (28-30). Downregulation of T-cadherin expression may be associated with the increased risk of malignant 
progression and may therefore represent a potential biomarker for certain types of cancer.

T-cadherin downregulation has been observed in malignant breast tumors (31) and is often methylated in primary and metastatic tumor tissues of patients with breast cancer (32). Toyooka et al (33) revealed that T-cadherin may function as a tumor suppressor gene in breast cancer. Taken together, these findings indicate that $\mathrm{T}$-cadherin may serve as a prognostic marker for breast cancer development (31-33). Breast cancer is usually classified into biologically distinct, behaviorally different subtypes by the presence of immunohistochemically detected markers (34); however, the immunohistological determination of $\mathrm{T}$-cadherin expression in breast cancer is rarely reported.

Previous studies revealed that a lack of T-cadherin expression was significantly associated with poorer prognosis of patients with axillary lymph node-positive breast cancer; a multivariate analysis demonstrated that T-cadherin expression was an independent prognostic factor for disease-free survival (DFS) $(\mathrm{P}=0.002)$, but not for overall survival (OS) $(\mathrm{P}=0.067)(35)$, indicating that there may be an association between the expression of T-cadherin and the prognosis of patients with axillary lymph node-positive breast cancer. To date, the role served by $\mathrm{T}$-cadherin in the prognosis and metastasis of TNBC remains unclear.

In the present study, immunohistochemistry was used to determine the T-cadherin expression in 106 formalin-fixed TNBC specimens. The current study aimed to assess the clinicopathological significance of T-cadherin expression, and examine whether T-cadherin expression was an independent predictor of survival of the patients with TNBC.

\section{Materials and methods}

Subjects. A total of 106 females with TNBC who were enrolled in the Jining No. 1 People's Hospital (Jining, China) between January 2003 and December 2009 were randomly chosen for the present study (age range, 22-75 years; mean age, 49.6 years). Patients with invasive breast carcinoma were enrolled; patients with invasive lobular carcinoma were excluded. All patients underwent chemotherapy or chemotherapy in combination with radiotherapy, as detailed in Table I. All patients provided written informed consent.

All tissues were immediately fixed in $10 \%$ formalin for $24 \mathrm{~h}$ and embedded in paraffin. The clinicopathological features were collected retrospectively and analyzed. According to the results of pathological immunohistochemistry, the 106 patients were divided into two groups, T-cadherin-negative and T-cadherin-positive. The present study was approved by the Ethics Committee of Jining No. 1 People's Hospital (Jining, China). No significant differences were identified in the clinicopathological information between the two groups. Demographic data of the patients are listed in Table I.

Immunohistochemical (IHC) staining. Staining was performed as described previously (35). The following reagents were used for the IHC assay and all purchased from Fuzhou Maixin Biotechnology Development Co. Ltd. (Fuzhou, China): 3,3'-diaminobenzidine (DAB) color liquid, mouse anti-human T-cadherin monoclonal antibody (catalog no. H00001012-M01A; dilution, 1:100), Tris-buffered saline, an UltraSensitive ${ }^{\mathrm{TM}}$ SP (mouse) IHC kit (KIT-9702) and PBS. The immunoreactive products were visualized using a light microscope by the catalysis of DAB using horseradish peroxidase in the presence of $\mathrm{H}_{2} \mathrm{O}_{2}$ following extensive washing (magnification, x200). A total of 22 fields of view were assessed and images were captured using a DP25 camera (Olympus Corporation, Tokyo, Japan).

Positive staining of T-cadherin was primarily observed at the cell membrane. For semi-quantitative analysis, the positive cell staining intensity and percentage of cells stained per slide were scored. The results of staining were $(-),(+),(++)$, and (+++) according to T-cadherin expression level. (-) and $(+)$ indicated that T-cadherin expression was negative, while $(++)$ and $(+++)$ indicated that T-cadherin expression was positive (36). Staining intensity was determined as follows: 0 , no color; 1 , light yellow; 2 , brown; 3 , tan. The percentage of positively stained cells was defined as: $0, \leq 20 \% ; 1,21-50 \% ; 2$, $51-75 \% ; 3,>75 \%$. The final scores were calculated by considering the percentage of positively stained cells and staining intensity results, as previously described (37): negative (-), 0 ; weak positive $(+), 1-3$; medium positive $(++), 4-6$; strong positive $(+++), 7-9$. The immunohistochemical assessment was performed independently by two experienced pathological physicians.

Determination of ER/PR/HER-2. The presence of HER-2 was determined using a HercepTest kit (DakoCytomation, Carpinteria, CA, USA) according to manufacturer's protocol. The presence of PR and ER was determined immunohistochemically, using a monoclonal antibody targeted at PR (clone 16; cat no. ORG-8721; pre-diluted) and a monoclonal antibody targeted at ER (clone 611; cat no. ORG-8871; pre-diluted) (both from Leica Microsystems, Inc., Buffalo Grove, IL, USA), according to previously published procedures (38).

Follow up. Patients were followed up for 5 years. The 5-year DFS was used to determine the primary endpoint and 5-year OS was used to determine the secondary endpoint. DFS referred to the interval from the time of surgery to the time of such events as local relapse, distant metastasis, death from any cause, or the last follow-up. The interval from the time of surgery to the time of death or the last follow-up was used to define OS.

Statistical analysis. All data were analyzed using SPSS statistical software (version 17.0; SPSS, Inc., Chicago, IL, USA). Besides T-cadherin expression, the following clinicopathological parameters were analyzed: Family history, age, menopausal status, lymph node status, lymph-vascular invasion, tumor size, histological grade [Elston-Ellis modification of Bloom-Richardson grading system; Bloom-Richardson-Elston (BRE) score] (39), pathological status and histological disease type (36). A $\chi^{2}$ test was employed to analyze the association between $\mathrm{T}$-cadherin expression and the clinicopathological parameters. Survival curves based on T-cadherin expression were estimated using the Kaplan-Meier product-limit method, and the log-rank test was used to determine the influence of the T-cadherin expression on 5-year DFS and OS. Kaplan-Meier function and Cox regression analyses were used to analyze 
Table I. Association between T-cadherin expression and clinicopathological parameters in 106 patients with triple-negative breast cancer.

\begin{tabular}{|c|c|c|c|c|}
\hline Parameters & T-cadherin-negative, n (\%) & T-cadherin-positive, $\mathrm{n}(\%)$ & $\chi^{2}$ & P-value \\
\hline \multicolumn{5}{|l|}{ Age at surgery, years } \\
\hline$\leq 55$ & $53(75.7)$ & $21(58.3)$ & & \\
\hline$>55$ & $17(24.3)$ & $15(41.7)$ & 3.408 & 0.065 \\
\hline \multicolumn{5}{|l|}{ Menopausal status } \\
\hline Yes & $23(32.9)$ & $16(44.4)$ & & \\
\hline No & $47(67.1)$ & $20(55.6)$ & 1.373 & 0.241 \\
\hline \multicolumn{5}{|l|}{ Tumor size, $\mathrm{cm}$} \\
\hline$\leq 2$ & $14(20.0)$ & $15(41.7)$ & & \\
\hline$>2$ & $56(80.0)$ & $21(58.3)$ & 5.616 & 0.018 \\
\hline \multicolumn{5}{|l|}{ BRE grade (39) } \\
\hline I & $17(24.3)$ & $17(47.2)$ & & \\
\hline II and III & $53(75.7)$ & $19(52.8)$ & 5.740 & 0.017 \\
\hline \multicolumn{5}{|l|}{ Lymph-vascular invasion } \\
\hline Negative & $39(55.7)$ & $17(47.2)$ & & \\
\hline Positive & $31(44.3)$ & $19(52.8)$ & 0.688 & 0.407 \\
\hline \multicolumn{5}{|l|}{ Lymph node status } \\
\hline Negative & $23(32.9)$ & $19(52.8)$ & & \\
\hline Positive & $47(67.1)$ & $17(47.2)$ & 3.944 & 0.047 \\
\hline \multicolumn{5}{|l|}{ Histological type } \\
\hline IDC & $63(90.0)$ & $33(91.7)$ & & \\
\hline Special type & $7(10.0)$ & $3(8.3)$ & 0.077 & 0.781 \\
\hline \multicolumn{5}{|l|}{ Family history } \\
\hline No & $57(81.4)$ & $29(80.6)$ & & \\
\hline Yes & $13(18.6)$ & $7(19.4)$ & 0.012 & 0.093 \\
\hline \multicolumn{5}{|l|}{ TNM stage (40) } \\
\hline $\mathrm{I} / \mathrm{II}$ & $51(72.9)$ & $28(77.8)$ & & \\
\hline III & $19(27.1)$ & $8(22.2)$ & 0.303 & 0.582 \\
\hline \multicolumn{5}{|l|}{ Therapy } \\
\hline Chemotherapy + radiotherapy & $49(70.0)$ & $14(38.9)$ & & \\
\hline Chemotherapy & $21(30.0)$ & $22(61.1)$ & 9.544 & 0.002 \\
\hline \multicolumn{5}{|l|}{ Follow up } \\
\hline Death & $17(24.3)$ & $2(5.6)$ & & \\
\hline Regional recurrence & $3(4.3)$ & $1(2.8)$ & & \\
\hline Distant metastasis & $23(32.9)$ & $4(11.1)$ & & \\
\hline Lost follow-up & $2(2.9)$ & $1(2.8)$ & 1.396 & 0.706 \\
\hline
\end{tabular}

BRE, Bloom-Richardson-Elston; TNM, tumor-node-metastasis.

DFS and OS. $\mathrm{P}<0.05$ was considered to indicate a statistically significant difference.

\section{Results}

T-cadherin expression is associated with clinicopathological parameters. Of the 106 patients with TNBC, T-cadherin-negative patients accounted for $66.04 \%$ (70/106), and T-cadherin-positive patients accounted for $33.96 \%(36 / 106)$. T-cadherin protein was expressed at the cell membrane (Fig. 1) according to the results of immunohistochemical analysis. No significant differences were identified between the two groups in terms of family history, age, lymph-vascular invasion, pathological stage [tumor-node-metastasis (TNM) staging was assessed according to the staging system established by the American Joint Committee on Cancer] (40), histological types or menopausal status ( $\mathrm{P}>0.05$; Table I). However, tumor size $>2 \mathrm{~cm}$, BRE grade II and III, and positive lymph node status were more common in the negative group compared with the 
Table II. Prediction of axillary lymph node-positive breast cancer by univariate survival analysis on various clinicopathological parameters.

\begin{tabular}{|c|c|c|c|c|c|c|c|}
\hline Parameters & $\mathrm{n}$ & 5-year DFS, \% & $\chi^{2}$ & P-value & 5 -year OS, \% & $\chi^{2}$ & P-value \\
\hline \multicolumn{8}{|l|}{ Age at operation, years } \\
\hline$\leq 55$ & 74 & 68.92 & & & 79.73 & & \\
\hline$>55$ & 32 & 75.00 & 0.865 & 0.352 & 87.50 & 1.210 & 0.271 \\
\hline \multicolumn{8}{|l|}{ Menopausal status } \\
\hline Yes & 39 & 79.49 & & & 89.74 & & \\
\hline No & 67 & 65.67 & 3.032 & 0.082 & 77.61 & 2.872 & 0.090 \\
\hline \multicolumn{8}{|l|}{ Tumor size, $\mathrm{cm}$} \\
\hline$\leq 2$ & 29 & 79.31 & & & 86.20 & & \\
\hline$>2$ & 77 & 67.53 & 1.079 & 0.299 & 80.52 & 0.427 & 0.514 \\
\hline \multicolumn{8}{|l|}{ BRE grade (39) } \\
\hline I & 34 & 82.35 & & & 88.24 & & \\
\hline II and III & 72 & 65.28 & 2.203 & 0.138 & 79.17 & 1.018 & 0.313 \\
\hline \multicolumn{8}{|l|}{ Lymph-vascular invasion } \\
\hline Negative & 56 & 87.50 & & & 91.07 & & \\
\hline Positive & 50 & 52.00 & 16.780 & 0.001 & 72.00 & 5.996 & 0.014 \\
\hline \multicolumn{8}{|l|}{ Lymph node status } \\
\hline Negative & 42 & 85.71 & & & 92.86 & & \\
\hline Positive & 64 & 60.94 & 7.045 & 0.008 & 75.00 & 5.101 & 0.024 \\
\hline \multicolumn{8}{|l|}{ Histological type } \\
\hline IDC & 96 & 69.79 & & & 81.25 & & \\
\hline Special type & 10 & 80.00 & 0.390 & 0.532 & 90.00 & 0.435 & 0.510 \\
\hline \multicolumn{8}{|l|}{ Family history } \\
\hline No & 86 & 72.09 & & & 81.40 & & \\
\hline Yes & 20 & 65.00 & 0.036 & 0.849 & 85.00 & 0.724 & 0.395 \\
\hline \multicolumn{8}{|l|}{ TNM stage (40) } \\
\hline $\mathrm{I} / \mathrm{II}$ & 79 & 75.95 & & & 84.81 & & \\
\hline III & 27 & 55.56 & 4.795 & 0.029 & 74.07 & 1.437 & 0.231 \\
\hline \multicolumn{8}{|l|}{ T-cadherin } \\
\hline Negative & 70 & 62.86 & & & 75.71 & & \\
\hline Positive & 36 & 86.11 & 6.061 & 0.014 & 94.44 & 5.246 & 0.022 \\
\hline \multicolumn{8}{|l|}{ Therapy } \\
\hline Chemotherapy & 43 & 83.72 & & & 90.70 & & \\
\hline Chemotherapy + radiotherapy & 53 & 54.72 & 5.477 & 0.019 & 71.70 & 3.583 & 0.058 \\
\hline
\end{tabular}

DFS, disease-free survival; OS, overall survival; IDC, invasive ductal carcinoma; BRE, Bloom-Richardson-Elston; TNM, tumor-node-metastasis .

positive group (80.0 vs. $58.3,75.7$ vs. 52.8 , and 67.1 vs. $47.2 \%$, respectively; $\mathrm{P}=0.018, \mathrm{P}=0.017$, and $\mathrm{P}=0.047$ ) (Table I).

T-cadherin was associated with survival analyses. All 106 patients with TNBC were followed up for 5 years after surgery. In total, 31 (29.25\%) suffered recurrence, 19 (17.92\%) succumbed to the disease and $3(2.1 \%)$ were lost to follow-up during the 5 years. Of the 70 patients in the T-cadherin-negative group, 26 (37.14\%) suffered recurrence and 17 (24.29\%) succumbed to the disease. The mean DFS of this group was 3.99 years, with a mean OS of 4.58 years. The 5 -year DFS rate was $70.75 \%$, with the 5 -year OS rate of $82.08 \%$. Of the 36 patients in the T-cadherin-positive expression group, 5
(13.89\%) suffered recurrence and $2(5.56 \%)$ succumbed to the disease. The mean DFS was 4.69 years, and mean OS was 4.89 years. The 5-year DFS was $86.11 \%$, with a 5 -year OS of $94.44 \%$. The influence of the T-cadherin expression on 5-year DFS and 5-year OS was determined using the log-rank test. The 5-year DFS and 5-year OS of the T-cadherin-negative group were lower compared with those of the T-cadherin-positive group $(\mathrm{Z}=6.233, \mathrm{P}=0.013 ; \mathrm{Z}=5.366, \mathrm{P}=0.021$ ) (Fig. 2 ).

In terms of univariate survival analysis (Table II), there were shorter DFS $(\mathrm{P}=0.014)$ and $\mathrm{OS}(\mathrm{P}=0.022)$ for T-cadherin-negative patients compared with T-cadherin-positive patients. Lymph-vascular invasion was associated with a significantly shorter DFS $(\mathrm{P}=0.001)$ and OS $(\mathrm{P}=0.014)$, and 

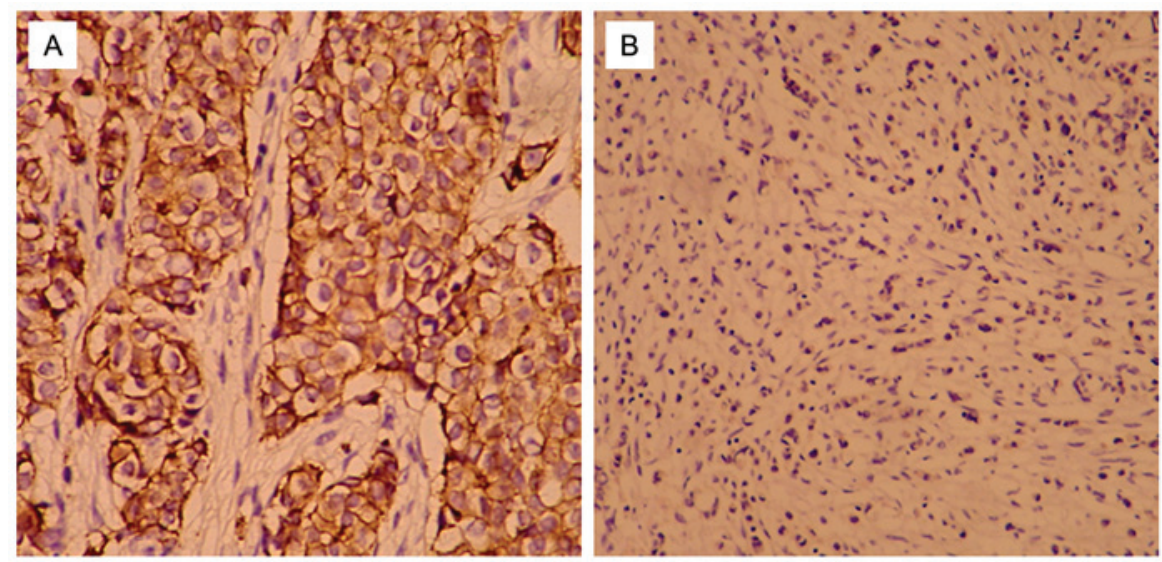

Figure 1. Immunohistochemical analysis of T-cadherin expression levels in human breast cancer. (A) Positive expression of T-cadherin was observed in triple-negative breast cancer (SP staining, magnification, x200). (B) Negative expression of T-cadherin was observed in triple-negative breast cancer (SP staining, magnification, $\mathrm{x} 200$ ).
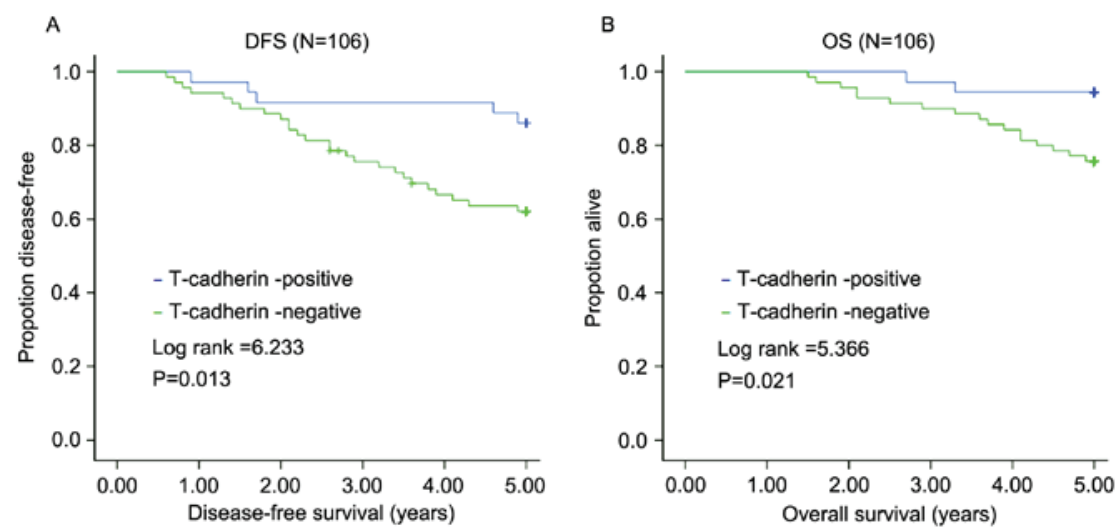

Figure 2. Positive T-cadherin expression is associated with a higher DFS and OS. (A) Association between T-cadherin expression and DFS. (B) Association between T-cadherin expression and OS. DFS, disease-free survival; OS, overall survival.

Table III. Multivariate analyses of disease-free survival of 106 patients with triple-negative breast cancer.

$95.0 \%$ CI for RR

\begin{tabular}{|c|c|c|c|c|c|c|c|}
\hline \multirow[b]{2}{*}{ Parameters } & \multirow[b]{2}{*}{$\mathrm{B}$} & \multirow[b]{2}{*}{ SE } & \multirow[b]{2}{*}{ Wald } & \multirow[b]{2}{*}{ P-value } & \multirow[b]{2}{*}{ RR } & \\
\hline & & & & & & Lower & Upper \\
\hline Age at operation & 9.248 & 98.070 & 0.009 & 0.925 & $10,384.712$ & 0.000 & $3.119 \times 10^{87}$ \\
\hline Menopausal status & -10.025 & 98.070 & 0.010 & 0.919 & 0.000 & 0.000 & $1.328 \times 10^{79}$ \\
\hline Tumor size & -1.697 & 0.822 & 4.255 & 0.039 & 0.183 & 0.037 & 0.919 \\
\hline BRE grade (39) & 0.858 & 0.515 & 2.770 & 0.096 & 2.358 & 0.859 & 6.474 \\
\hline TNM stage (40) & 0.737 & 0.405 & 3.311 & 0.069 & 2.090 & 0.945 & 4.622 \\
\hline Lymph node status & 0.132 & 0.667 & 0.039 & 0.843 & 1.141 & 0.309 & 4.222 \\
\hline Lymph-vascular invasion & 2.050 & 0.527 & 15.148 & $<0.001$ & 7.767 & 2.766 & 21.805 \\
\hline Histological type & 0.814 & 0.748 & 1.186 & 0.276 & 2.258 & 0.521 & 9.779 \\
\hline Family history & -0.193 & 0.472 & 0.167 & 0.683 & 0.825 & 0.327 & 2.081 \\
\hline T-cadherin & 1.350 & 0.519 & 6.758 & 0.009 & 3.858 & 1.394 & 10.674 \\
\hline Radiotherapy & 0.723 & 0.741 & 0.952 & 0.329 & 2.061 & 0.482 & 8.807 \\
\hline
\end{tabular}

B, partial regression coefficient; SE, standard error; RR, relative risk; CI, confidence interval; BRE, Bloom-Richardson-Elston; TNM, tumor-node-metastasis.

positive lymph node status was associated with a significantly shorter DFS $(\mathrm{P}=0.008)$ and OS $(\mathrm{P}=0.024)$. TNM staging
III was associated with a significantly shorter DFS only $(\mathrm{P}=0.029)$ (Table II). 
Table IV. Multivariate analyses on overall survival of 106 patients with triple-negative breast cancer.

$95.0 \%$ CI for RR

\begin{tabular}{lrrrrrrr}
\cline { 4 - 7 } Parameters & \multicolumn{1}{c}{$\mathrm{B}$} & $\mathrm{SE}$ & Wald & P-value & RR & Lower & Upper \\
\hline Age at operation & 9.427 & 133.133 & 0.005 & 0.944 & $12,418.991$ & 0.000 & $2.612 \times 10^{117}$ \\
Menopausal status & -10.254 & 133.132 & 0.006 & 0.939 & 0.000 & 0.000 & $7.387 \times 10^{108}$ \\
Tumor size & -2.349 & 1.278 & 3.381 & 0.066 & 0.095 & 0.008 & 1.167 \\
BRE grade (39) & 0.773 & 0.673 & 1.319 & 0.251 & 2.166 & 0.579 & 8.102 \\
TNM stage (40) & 0.503 & 0.522 & 0.929 & 0.335 & 1.654 & 0.594 & 4.606 \\
Lymph node status & 1.009 & 0.885 & 1.298 & 0.255 & 2.742 & 0.483 & 15.551 \\
Lymph-vascular invasion & 1.308 & 0.580 & 5.081 & 0.024 & 3.700 & 1.186 & 11.542 \\
Histological type & 0.711 & 1.048 & 0.460 & 0.497 & 2.036 & 0.261 & 15.876 \\
Family history & -1.207 & 0.764 & 2.495 & 0.114 & 0.299 & 0.067 & 1.337 \\
T-cadherin & 1.534 & 0.776 & 3.910 & 0.048 & 4.636 & 1.014 & 21.207 \\
Radiotherapy & 1.253 & 1.138 & 1.213 & 0.271 & 3.502 & 0.377 & 32.575 \\
\hline
\end{tabular}

B, partial regression coefficient; SE, standard error; RR, relative risk; CI, confidence interval; BRE, Bloom-Richardson-Elston; TNM, tumor-node-metastasis.

In terms of multivariate Cox regression analysis, lymph-vascular invasion and tumor size $>2 \mathrm{~cm}$ (Wald $=15.148$ and Wald $=4.255$, respectively; $\mathrm{P}<0.001$ and $\mathrm{P}=0.039$, respectively) were other factors that reached significance for predicting DFS (Table III). Lymph-vascular invasion was a factor that reached significance for predicting OS (Wald =5.081; $\mathrm{P}=0.024$; Table IV). Furthermore, T-cadherin expression was an independent prognostic factor for DFS (Wald =6.758; $\mathrm{P}=0.009$; Table III) and OS (Wald =3.910; $\mathrm{P}=0.048$; Table IV).

\section{Discussion}

According to the current study, patients with negative T-cadherin expression were associated with more aggressive TNBC clinicopathological features. The DFS and OS of the patients with T-cadherin-negative expression were decreased.

To the best of our knowledge, the present study is the first to perform immunohistochemical analysis on T-cadherin expression in TNBC. A significant association was identified between negative T-cadherin expression and a tumor size $>2 \mathrm{~cm}$, histological grade II and III, and positive lymph node status in TNBC $(\mathrm{P}<0.05)$. Negative T-cadherin expression was significantly associated with poor TNBC patient prognosis. Multivariate analysis revealed that T-cadherin expression was an independent prognostic factor for DFS $(\mathrm{P}=0.009)$ and OS $(\mathrm{P}=0.048)$.

There are several limitations to the present study. First, the sample size was small, which reduced the power of the study, and a number of patients were lost in follow-up, reducing the power further. Second, patients with invasive lobular carcinoma were excluded, thus whether invasive lobular carcinoma had altered T-cadherin expression remains unknown. Third, data at the molecular/genetic level were not provided. It is hoped that a large-sample multi-center study will be performed in the future, verifying the findings of the present study.
According to the results of the current study, T-cadherin expression was associated with the clinicopathological features and prognosis of TNBC. For patients with TNBC, T-cadherin-negative expression was a prognostic factor, and T-cadherin may serve as a marker of TNBC, contributing to more precise prediction of prognosis.

\section{Acknowledgements}

The present study was supported by the Science and Technology Development Plan of Jining No. 1 People's Hospital (grant no. 2014jnjc14).

\section{References}

1. He Y, Mou J, Luo D, Gao B and Wen Y: Primary malignant melanoma of the breast: A case report and review of the literature. Oncol Lett 8: 238-240, 2014.

2. Li FY, Wu SG, Zhou J, Sun JY, Lin Q, Lin HX, Guan XX and He ZY: Prognostic value of Ki-67 in breast cancer patients with positive axillary lymph nodes: A retrospective cohort study. PLoS One 9: e87264, 2014.

3. Early Breast Cancer Trialists' Collaborative Group (EBCTCG): Effects of chemotherapy and hormonal therapy for early breast cancer on recurrence and 15-year survival: An overview of the randomised trials. Lancet 365: 1687-1717, 2005.

4. Fornier M and Fumoleau P: The paradox of triple negative breast cancer: Novel approaches to treatment. Breast J 18: 41-51, 2012.

5. Dent R, Trudeau M, Pritchard KI, Hanna WM, Kahn HK, Sawka CA, Lickley LA, Rawlinson E, Sun P and Narod SA: Triple-negative breast cancer: Clinical features and patterns of recurrence. Clin Cancer Res 13: 4429-4434, 2007.

6. Millikan RC, Newman B, Tse CK, Moorman PG, Conway K, Dressler LG, Smith LV, Labbok MH, Geradts J, Bensen JT, et al: Epidemiology of basal-like breast cancer. Breast Cancer Res Treat 109: 123-139, 2008.

7. D'Ippolito $\mathrm{E}$ and Iorio MV: MicroRNAs and triple negative breast cancer. Int J Mol Sci 14: 22202-22220, 2013.

8. McNamara KM, Yoda T, Nurani AM, Shibahara Y, Miki Y, Wang L, Nakamura Y, Suzuki K, Yang Y, Abe E, et al: Androgenic pathways in the progression of triple-negative breast carcinoma: A comparison between aggressive and non-aggressive subtypes. Breast Cancer Res Treat 145: 281-293, 2014. 
9. Jang NY, Kim DH, Cho BJ, Choi EJ, Lee JS, Wu HG, Chie EK and Kim IA: Radiosensitization with combined use of olaparib and PI-103 in triple-negative breast cancer. BMC Cancer 15: 89, 2015.

10. Liu P, Tang H, Chen B, He Z, Deng M, Wu M, Liu X, Yang L, Ye $\mathrm{F}$ and Xie $\mathrm{X}$ : miR-26a suppresses tumour proliferation and metastasis by targeting metadherin in triple negative breast cancer. Cancer Lett 357: 384-392, 2015.

11. Bisso A, Faleschini M, Zampa F, Capaci V, De Santa J, Santarpia L, Piazza S, Cappelletti V, Daidone M, Agami R and Del Sal G: Oncogenic miR-181a/b affect the DNA damage response in aggressive breast cancer. Cell Cycle 12: 1679-1687, 2013.

12. Ma F, Li H, Wang H, Shi X, Fan Y, Ding X, Lin C, Zhan Q, Qian H and Xu B: Enriched CD44(+)/CD24(-) population drives. the aggressive phenotypes presented in triple-negative breast cancer (TNBC). Cancer Lett 353: 153-159, 2014.

13. van Roy F: Beyond E-cadherin: Roles of other cadherin superfamily members in cancer. Nat Rev Cancer 14: 121-134, 2014.

14. Berx G and van Roy F: Involvement of members of the cadherin superfamily in cancer. Cold Spring Harb Perspect Biol 1: a003129, 2009 .

15. Andrews JL, Kim AC and Hens JR: The role and function of cadherins in the mammary gland. Breast Cancer Res 14: 203, 2012.

16. Gheldof A and Berx G: Cadherins and epithelial-to-mesenchymal transition. Prog Mol Biol Transl Sci 116: 317-336, 2013.

17. Philippova M, Joshi MB, Kyriakakis E, Pfaff D, Erne P and Resink TJ: A guide and guard: The many faces of T-cadherin. Cell Signal 21: 1035-1044, 2009.

18. Guillaume E, Comunale F, Do Khoa N, Planchon D, Bodin S and Gauthier-Rouvière C: Flotillin microdomains stabilize cadherins at cell-cell junctions. J Cell Sci 126: 5293-5304, 2013.

19. Adachi Y, Takeuchi T, Nagayama T, Ohtsuki Y and Furihata M: Zeb1- mediated T-cadherin repression increases the invasive potential of gallbladder cancer. FEBS Lett 583: 430-436, 2009.

20. Philippova M, Joshi MB, Pfaff D, Kyriakakis E, Maslova K, Erne P and Resink TJ: T-cadherin attenuates insulin dependent signalling, eNOS activation, and angiogenesis in vascular endothelial cells. Cardiovasc Res 93: 498-507, 2012.

21. Maslova K, Kyriakakis E, Pfaff D, Frachet A, Frismantiene A, Bubendorf L, Ruiz C, Vlajnic T, Erne P, Resink TJ and Philippova M: EGFR and IGF-1R in regulation of prostate cancer cell phenotype and polarity: Opposing functions and modulation by T- cadherin. FASEB J 29: 494-507, 2015.

22. Makarla PB, Saboorian MH, Ashfaq R, Toyooka KO, Toyooka S, Minna JD, Gazdar AF and Schorge JO: Promoter hypermethylation profile of ovarian epithelial neoplasms. Clin Cancer Res 11: $5365-5369,2005$

23. Tang Y, Dai Y and Huo J: Decreased expression of T-cadherin is associated with gastric cancer prognosis. Hepatogastroenterology 59: 1294-1298, 2012.

24. Toyooka S, Toyooka KO, Harada K, Miyajima K, Makarla P, Sathyanarayana UG, Yin J, Sato F, Shivapurkar N, Meltzer SJ and Gazdar AF: Aberrant methylation of the CDH13 (H-cadherin) promoter region in colorectal cancers and adenomas. Cancer Res 62: 3382-3386, 2002.

25. Li DL, Zhang ZQ, Chen SH, Zhang SA, Fang J, Lin ZQ, Zhang X and Jiang Y: Expression of T-cadherin in hepatocellular carcinoma and its relationship with relapse and metastasis of tumor. Med J Chin PLA 40: 315-318, 2015.
26. Lin Y, Sun G, Liu X, Chen Y and Zhang C: Clinical significance of T-cadherin tissue expression in patients with bladder transitional cell carcinoma. Urol Int 86: 340-345, 2011.

27. Takeuchi T, Misaki A, Chen BK and Ohtsuki Y: H-cadherin expression in breast cancer. Histopathology 35: 87-88, 1999.

28. Ciatto C, Bahna F,Zampieri N, VanSteenhouse HC, Katsamba PS, Ahlsen G, Harrison OJ, Brasch J, Jin X, Posy S, et al: T-cadherin structures reveal a novel adhesive binding mechanism. Nat Struct Mol Biol 17: 339-347, 2010.

29. Andreeva AV and Kutuzov MA: Cadherin 13 in cancer. Genes Chromosomes Cancer 49: 775-790, 2010.

30. Ellmann L, Joshi MB, Resink TJ, Bosserhoff AK and Kuphal S: BRN2 is a transcriptional repressor of CDH13 (T-cadherin) in melanoma cells. Lab Invest 92: 1788-1800, 2012.

31. Lee SW: H-cadherin, a novel cadherin with growth inhibitory functions and diminished expression in human breast cancer. Nat Med 2: 776-782, 1996.

32. Feng W, Orlandi R, Zhao N, Carcangiu ML, Tagliabue E, Xu J, Bast RC Jr and $\mathrm{Yu}$ Y: Tumor suppressor genes are frequently methylated in lymph node metastases of breast cancers. BMC Cancer 10: 378, 2010

33. Toyooka KO, Toyooka S, Virmani AK, Sathyanarayana UG, Euhus DM, Gilcrease M, Minna JD and Gazdar AF: Loss of expression and aberrant methylation of the CDH13 (H-cadherin) gene in breast and lung carcinomas. Cancer Res 61: 4556-4560, 2001.

34. Bradshaw SH, Pidutti D, Gravel DH, Song X and Robertson SJ: Predicting OncoDX recurrence scores with immunohistochemical markers: effect of stromelysin. Appl Immunohistochem Mol Morphol 23: 26-30, 2015.

35. Kong DD, Yang J, Li L, Wang W, Chen YN, Wang SB and Zhou YZ: T-cadherin association with clinicopathological features and prognosis in axillary lymph node-positive breast cancer. Breast Cancer Res Treat 150: 119-126, 2015.

36. Celebiler Cavusoglu A, Kilic Y, Saydam S, Canda T, Başkan Z, Sevinc AI and Sakizli M: Predicting invasive phenotype with $\mathrm{CDH} 1, \mathrm{CDH} 13, \mathrm{CD} 44$, and TIMP3 gene expression in primary breast cancer. Cancer Sci 100: 2341-2345, 2009.

37. Qasim BJ, Ali HH and Hussein AG: Immunohistochemical expression of matrix metalloproteinase-7 in human colorectal adenomas using specified automated cellular image analysis system: A clinicopathological study. Saudi J Gastroenterol 19 23-27, 2013

38. Cimino-Mathews A, Hicks JL, Illei PB, Halushka MK, Fetting JH, De Marzo AM, Park BH and Argani P: Androgen receptor expression is usually maintained in initial surgically resected breast cancer metastases but is often lost in end-stage metastases found at autopsy. Hum Pathol 43: 1003-1011, 2012.

39. Lebok P, Öztürk M, Heilenkötter U, Jaenicke F, Müller V, Paluchowski P, Geist S, Wilke C, Burandt E, Lebeau A, et al: High levels of class III $\beta$-tubulin expression are associated with aggressive tumor features in breast cancer. Oncol Lett 11: 1987-1994, 2016

40. Tao Y, Mao J, Zhang Q and Li L: Overexpression of Hedgehog signaling molecules and its involvement in triple-negative breast cancer. Oncol Lett 2: 995-1001, 2011. 